\title{
Influence of skeletal maturation on physical fitness of young people with Down syndrome
}

http://dx.doi.org/10.11606/1807-5509202000030373

\author{
Everaldo Lambert Modesto* \\ Leonardo dos Santos Oliveira" \\ Bruna Barboza Seron ** \\ Eloise Werle de Almeida* \\ Márcia Greguol
}

${ }^{*}$ Department of Sport Science, State University of Londrina, Londrina, PR, Brazil. ${ }^{* *}$ Department of Physical Education, Federal University of Santa Catarina, Florianópolis, SC, Brazil.

\begin{abstract}
Individuals with Down syndrome (DS) tend to prematurely reach the skeletal maturation period. In addition, young people with this condition have poor physical fitness and few opportunities to practice physical activity when compared to those without disabilities. The aim of this study was to investigate the skeletal maturation of young people with Down syndrome and its influence on the behavior of physical fitness related to health, after aerobic and resistance training programs. Forty people with DS, with an average age of $15.4( \pm 2.6)$ years, were divided into three groups for a 12 weeks intervention program, AT - aerobic training group (3 times/week; 50 minutes/session), RT - resistance training group (twice/ week ; 50 minutes/session) and CG - control group, 9 participants. Determination of skeletal age (EA) was performed using the Greulich-Pyle method. Anthropometric variables, muscle strength and peak $\mathrm{VO}_{2}$ were measured pre and post intervention. It was found that skeletal maturation influenced the effects of training, only being significant for body weight and strength in the upright row variables. In addition, the muscle strength of upper and lower limbs increased significantly after 12 weeks of aerobic or resistance training. Then, we can conclude that the effects of physical training on physical fitness of young people with Down syndrome appear to improve as the bone age increases.
\end{abstract}

KEYwords: Exercise Training; Intellectual Disability; Physical Fitness; Skeletal Age.

\section{Introduction}

The growth and development of human beings is a gradual process from the moment of conception until death, revealing interesting parameters associated with a number of quantitative and qualitative physical transformations that represent the evolution itself $f^{1,2}$. These changes occur in different rhythms and intensities, depending on the stage of life in which the human being is.

In the case of people with intellectual disability, these changes occur at different rates compared to people with typical development. According to the American Association on Intellectual and Developmental Disabilities ${ }^{3}$, about $5 \%$ of the population has some type of intellectual disability. Down syndrome (DS) is an important cause of this type of disability and the most common among all syndromes that affect humans, affecting about one in every 750 live births $s^{4,5}$.

The chronological age, i.e., the period between birth and the individual's age, by itself, is not a sufficient criterion for growth and development analysis. Accordingly, some authors have carried out studies in order to relate chronological age to other biological indices, such as height, weight, and skeletal age, in order to understand the relationship between chronological age and the stage of an individual's physical and mental maturation ${ }^{1,6,7}$.

In this context, some studies report that the level of attained performance is more dependent on skeletal age than chronological age ${ }^{8-10}$, and that some variables, closely related to health and quality of life of any person, such as muscle strength and $\mathrm{VO}_{2 \max }$, 
increase with age and maturation ${ }^{11}$. However, it is known that these changes occur in different rhythms and intensities, according to experiences and the stage of life in which the individual is.

Especially in people with Down syndrome, studies related to skeletal maturation point out that these individuals tend to prematurely reach the maturation period in relation to the population without disabilities ${ }^{12-15}$. Thus, with regard to skeletal maturation, this phenomenon compromises the speed of height gain, with implications on the final height of individuals with $\mathrm{DS}^{13}$.

Some DS characteristics such as muscular hypotonia, prevalence of heart disease, abnormalities in the circulatory and respiratory system and low maximum heart rate, mean that individuals with this syndrome can demonstrate alterations in development, including physical fitness indicators ${ }^{16}$. In this sense, people with Down syndrome present more negative values of body composition, cardiorespiratory fitness and muscle strength when

\section{Method}

\section{Research participants}

This study was approved by the Committee of Ethics in Research with Human Beings of the State University of Londrina (protocol number $1.215 .776 / 2015$ ). The study included 40 participant $s$ with Down syndrome of both sexes, aged between 12 and 20 years, 25 males and 15 females. All participants were contacted in care institutions of the city of Londrina/PR/ Brazil. The young people had a medical certificate enabling them to participate in the study, and along with their parents or legal guardians signed a consent form prior to participation. The exclusion criteria were: individuals who had orthopedic or cardiac impairment, atlantoaxial instability, used drugs that alter heart rate or presented severe or profound intellectual disabilities that prevented understanding and/or completion of the procedures. The study was approved by the Ethics Committee of the State University of Londrina.

The young people were randomly divided into three groups: AT - aerobic training group, with 16 participants (five girls and eleven boys); RT resistance training group, with 15 participants (five compared to their non-disabled peers ${ }^{17,18}$.

As an aggravating factor, according to SERON and GREGUOL ${ }^{19}$, a physically active lifestyle is not common among people with disabilities, and when dealing with DS there is a still greater predisposition to a sedentary lifestyle. This condition has been identified as one of the reasons for obesity and low levels of physical fitness, and possible limitations on the motor repertoire in this population ${ }^{16,19,20}$. Despite the relevance of the theme, although we hypothesized that skeletal maturation exert positive influence on physical training, we didn't localize studies that correlated the level of skeletal maturation to the type of training for young people with Down syndrome. Thus, given the importance of the topic, the objective of this study was to investigate the skeletal maturation of young people with Down syndrome and its influence on the behavior of some variables of physical fitness related to health, after aerobic and resistance training programs.

girls and ten boys) and CG - control group, with 9 participants (five girls and four boys). The control group, although beginning with 15 individuals, had a sample loss of six people, then finishing with nine participants. For participants' allocation, we choose simple randomization procedures, and a computer-generated list of random numbers was used.

\section{Questionnaires}

Two questionnaires were applied to the parents of the individuals with DS. The first consisted of questions about the young person's age and sex, gestational age, education, practice of physical activity and any other health condition associated with individuals with DS. The second questionnaire was related to the socioeconomic status of the families ${ }^{21}$. In presenting the results, we considered the classes A (high level), B (middle/ high level), C (middle/low level) and D (low level).

\section{Physical Assessment}

Cardiorespiratory fitness, body composition and strength of the study participants were evaluated 
at two distinct moments, before and after a 12week intervention program. The skeletal age of the participants was also evaluated during the seventh week of the intervention.

\section{Cardiorespiratory fitness}

Cardiorespiratory fitness (peak oxygen consumption - peak $\mathrm{VO}_{2}$ ) was assessed through a maximal exercise test with a protocol validated for people with Down syndrome ${ }^{22}$. This test was performed on a treadmill (Inbramed, model 10200) with the use of a portable ergospirometer $\left(\mathrm{k} 4 \mathrm{~b}^{2}\right.$ Cosmed, Italy) and consisted of an initial speed of $4 \mathrm{~km} / \mathrm{h}$ and $0 \%$ slope for two minutes followed by a slope increase of $2.5 \%$ every two minutes up to a maximum height of $12.5 \%$. From this moment on, the speed was increased $1.6 \mathrm{~km} / \mathrm{h}$ every minute until exhaustion. A familiarization session with a light walk in different inclinations was performed prior to the test.

\section{Body composition}

The body composition assessment (\% body fat, \% lean body mass and body density) was performed through plethysmography using BODPOD ${ }^{\circledR}$ equipment (Life Measurement Inc, Concord, CA). Waist circumference was also verified (using a flexible tape of 2 meters) and body mass index (BMI), by dividing body weight measured in kilograms (measured on a digital scale with a precision of 100 grams) by height in meters squared (measured on a stadiometer with a resolution of $0.1 \mathrm{~cm}$ ).

\section{Muscle strength}

Muscle strength of the lower (LL) and upper limbs (UL) was measured by applying a onerepetition maximum test (1RM) in two exercises: leg extension and upright row. The test is represented by the maximum amount of weight lifted once during the performance of a standardized weight lifting exercise. To test the 1RM for each muscle group, a weight of the exercise device was chosen, however, below the maximum individual lifting capacity. If a repetition was completed, load was added to the exercise device, to achieve maximum lifting capacity. Load increases were 1-5 kg during the evaluation period. This technique is commonly used with dumbbells and conventional devices in gyms $s^{23}$ and it is considered a reliable method for people with Down syndrome ${ }^{24}$. Execution of the $1 \mathrm{RM}$ tests was individually accompanied by the main researcher.

\section{Dynamometry}

Grip strength was measured using a hydraulic dynamometer (JAMAR Preston Corporation., USA). The test was performed on both the right and left hand, with a one-minute interval between attempts, following the recommendations of the American Society of Hand Therapists ${ }^{25}$; three attempts were allowed. The young people exerted palmar pressure with the greatest possible isometric contraction, maintained for five seconds, with the arm beside the trunk, elbow flexed at a $90^{\circ}$ angle and wrist in a neutral position. The highest score was considered for each hand. The grip strength dynamometry is considered a valid method for people with intellectual disabilities ${ }^{26}$.

\section{Biological maturation - skeletal age}

Determination of skeletal age (SA) was performed through the Greulich-Pyle method ${ }^{27}$. This method compares the radiograph of an individual's hand and left wrist with a set of X-rays that characterize successive maturational stages of development at different chronological ages for each sex. The individual is designated a bone age equal to that of the pattern their X-ray resembles. A total of 28 ossification points are examined during the comparison.

The classification level of maturity was based on the difference between skeletal age and chronological age (CA-SA). Any participant who presented a difference between CA and SA ages within \pm 1 year was rated as normal maturation. Participants whose bone age was delayed by more than one year relative to their chronological age were designated as delayed maturation. Likewise, participants whose bone age was advanced by more than one year in relation to chronological age were designated as advanced maturation ${ }^{28}$.

\section{Training Program}

The training program consisted of 12 weeks, each session lasting about 50 minutes. Training was carried out at the gym located at the State University of Londrina. 


\section{Resistance training sessions}

The resistance training program (RT) sessions lasted 50 minutes and were performed twice a week on alternate days. The training was composed of two sets of 12 maximum repetitions of each exercise involving the upper limbs, lower limbs and abdominal, with one-minute intervals between sets and three minute intervals between exercises. The training program followed the alternate order by segment and the nine exercises were performed in the following order: bench press on a vertical bench, leg extension, pulley machine, lateral raises, standing leg curl with ankle weights, triceps pulley, calf vertical with ankle weights, pulley arm curl and curl-ups. The first two sessions were intended for adaptation to the exercises, with light loads and, from these, the load used was estimated by observing the ability to conduct this exercise for 12 maximum repetitions.

The progression of loads occurred spontaneously, insofar as the individual felt comfortable and could perform more than 12 repetitions in each exercise $^{29}$, that is, when 13 repetitions were performed in two sets.

\section{Aerobic training sessions}

The aerobic training program (AT) sessions lasted 50 minutes and each session was divided into: ten minute warm up, 30 minute aerobic workout on a treadmill and cycloergometer (15 minutes each), with a heart rate intensity between $50-70 \%$ of heart rate reserve, ending with ten minutes of cool down with stretching exercises. The maximum heart rate used for prescription intensity was obtained during a maximal exercise test, with a protocol validated for people with Down syndrome ${ }^{30}$. Heart rates of the participants were monitored continuously using a heart rate monitor (FT2, Polar, Finland). The aerobic training had a frequency of three weekly sessions, which were held on alternate days.

\section{Statistical analysis}

Initially, data of continuous variables were explored to verify the assumptions of normality (Shapiro-Wilk test) and homoscedasticity (Levene's test), and reported as mean and standard deviation or standard error. The response frequency (absolute and relative) for categorical variables was calculated, using Qui-square for comparisons. ANOVA was used to compare groups. The effects of the aerobic and resistance training, compared to the control group, were verified using analysis of covariance (ANCOVA) with post hoc Bonferroni, using the skeletal age and pre training measurements as covariates in the model. Furthermore, it was necessary to observe pre and post values for the $\mathrm{VO}_{\text {2peak }}$ of the control group with application of the paired $t$ test. Data were analyzed using the statistical program Statistica 10.0 (StatSoft Inc., USA), and in all situations a significance level $\mathrm{p}$ $<0.05$ was adopted.

\section{Results}

\section{Characteristics of the participants}

The descriptive data of the participants are shown in TABLE 1 . The study included 40 young people with Down syndrome, with an average age of 15.46 \pm 2.64 years, the majority were male $(62.5 \%)$, with a chronological age of 16 to $20(55.0 \%)$ and

TABLE 1 - Characterization of the study participants advanced skeletal age (65.\%). The age of the mother during pregnancy was below 34 years in $60.98 \%$ of cases and the most prevalent socioeconomic level corresponded to class C $(56.10 \%)$. In the comparisons between the three groups, there were no differences in chronological age and distribution in different socioeconomic levels.

\begin{tabular}{cc}
\hline & $\%(\mathrm{n}=\mathbf{4 0})$ \\
\hline Sex & \\
\hline Male & $62.50(25)$ \\
Female & $37.50(15)$ \\
\hline
\end{tabular}

continue 
continue

\begin{tabular}{cc}
\hline & $\%(\mathbf{n}=\mathbf{4 0})$ \\
\hline Age & \\
12 to 15 years & $45.00(18)$ \\
16 to 20 years & $55.00(22)$ \\
\hline Skeletal age & $15.0(06)$ \\
delayed & $65.0(26)$ \\
advanced & $20.0(08)$ \\
neutral & \\
Socioeconomiclevel & $2.44(1)$ \\
A & $36.59(15)$ \\
B & $56.10(23)$ \\
C & $4.88(1)$ \\
D & $60.98(25)$ \\
\hline Mother'spregnancy age & $39.02(15)$ \\
$\geq 35$ years & \\
\hline
\end{tabular}

Analysis of biological maturation according to skeletal age and sex

Regarding the absolute and relative frequencies of individuals according to their state of maturation, when observing TABLE 1 , it is possible to see that the majority of the young people presented advanced maturity in relation to chronological age; the study participants had a mean chronological age of $15.46 \pm 2.64$ years and skeletal age of $16.61 \pm$
2.15 years, demonstrating advanced SA compared to CA.

When analyzed the skeletal maturation through the $\mathrm{x}$-ray, there was no difference in the distribution of individuals at different levels between the three investigated groups. The distribution of relative frequencies of maturational status by sex is shown in FIGURE 1. In both sexes there was a greater number of young people with advanced skeletal age $(45.0 \%$ among boys and $53.3 \%$ among girls).

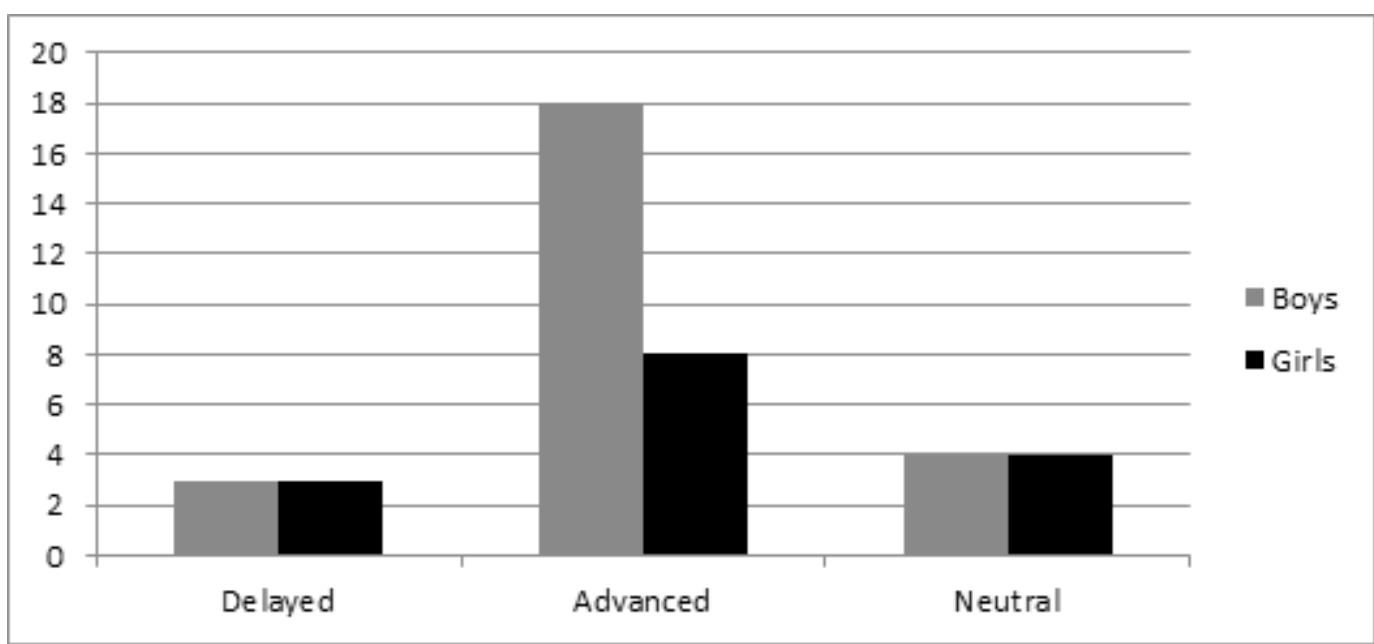

FIGURE 1-Relative frequency (\%) of young people classified by skeletal maturation stage according to sex.

TABLE 2 summarizes the comparison of training groups with the control group pre and post-intervention. It was found that skeletal maturation influenced the effects of training, only being significant for body weight variables, $\mathrm{F}$ (1, $38)=4.99 ; \mathrm{p}=.032 ; \mathrm{r}=0.34$, BMI, $\mathrm{F}(1,38)=$ $5.92 ; \mathrm{p}=.02 ; \mathrm{r}=.36$, and strength in the upright row, $\mathrm{F}(1,38)=6.93 ; \mathrm{p}=.013 ; \mathrm{r}=.39$. Thus, the 
skeletal maturation explained, respectively, $11.56 \%$, $12.96 \%$ and $15.21 \%$ of the variation provided by the intervention period in body weight, BMI and row strength. On the other hand, the trained groups presented higher $\mathrm{VO}_{2 \text { peak }}$ values $(\mathrm{p}=.001)$, time to exhaustion $(\mathrm{p}=.001)$ and power of the lower $(\mathrm{p}=$ $.001)$ and upper limbs ( $p=.001)$ compared to the control group.

TABLE 2-Effects of aerobic and resistance training on physical fitness of individuals with Down Syndrome ( $\mathrm{n}=40)$

Data presented as
mean and stan-
dard error adjusted
for skeletal age.
Significant diffe-
rence compared to
the control group
$(\mathrm{p}<0.05)$.

\begin{tabular}{|c|c|c|c|c|c|c|c|c|c|}
\hline \multirow{2}{*}{ Variable } & \multicolumn{2}{|c|}{ Control $(n=9)$} & \multicolumn{2}{|c|}{ Aerobic $(n=16)$} & \multicolumn{3}{|c|}{ Resistance $(n=15)$} & \multirow{2}{*}{ F } & \multirow{2}{*}{$\mathbf{P}$} \\
\hline & Pre & Post & Pre & Post & Pre & Post & & & \\
\hline $\begin{array}{l}\text { Bodymass } \\
(\mathrm{kg})\end{array}$ & $54.9 \pm 3.8$ & $55.4 \pm 3.8$ & $61.4 \pm 2.7$ & $60.8 \pm 3.0$ & $52.6 \pm 2.8$ & $52.5 \pm 2.9$ & .25 & 0.297 & .06 \\
\hline BMI $\left(\mathrm{kg} / \mathrm{m}^{2}\right)$ & $26.7 \pm 1.4$ & $26.8 \pm 1.5$ & $27.1 \pm 1.1$ & $26.2 \pm 1.1$ & $23.7 \pm 1.1$ & $23.1 \pm 1.1$ & .62 & 0.542 & .03 \\
\hline $\begin{array}{l}\text { Bodyadiposi- } \\
\text { ty }(\%)\end{array}$ & $27.4 \pm 3.0$ & $29.9 \pm 3.2$ & $30.7 \pm 2.1$ & $30.0 \pm 2.5$ & $23.6 \pm 2.2$ & $23.0 \pm 2.4$ & .76 & 0.077 & .13 \\
\hline $\begin{array}{l}\text { Abdominal } \\
\text { circumferen- } \\
\text { ce }(\mathrm{cm})\end{array}$ & $83.2 \pm 3.4$ & $84.3 \pm 3.6$ & $87.9 \pm 2.5$ & $86.0 \pm 2.8$ & $77.8 \pm 2.6$ & $77.6 \pm 2.6$ & .40 & 0.105 & .12 \\
\hline $\begin{array}{l}\mathrm{VO}_{2 \text { peak }}(\mathrm{mL} / \\
\mathrm{kg} / \mathrm{min})\end{array}$ & $29.9 \pm 1.7$ & $23.0 \pm 1.8$ & $29.8 \pm 1.3$ & $29.8 \pm 1.4^{*}$ & $31.3 \pm 1.3$ & $30.3 \pm 1.3 *$ & 1.02 & 0.001 & .38 \\
\hline $\begin{array}{l}\text { Time toe- } \\
\text { xhaustion (s) }\end{array}$ & $788 \pm 43$ & $729 \pm 26$ & $804 \pm 33$ & $902 \pm 20 *$ & $865 \pm 33$ & $911 \pm 20^{*}$ & .46 & 0.001 & .47 \\
\hline $\begin{array}{l}\text { Dinamome- } \\
\text { try (kgf) }\end{array}$ & $13.9 \pm 2.6$ & $13.4 \pm 2.6$ & $19.9 \pm 1.9$ & $19.9 \pm 2.0$ & $20.3 \pm 1.9$ & $21.6 \pm 1.9$ & .69 & 0.199 & .09 \\
\hline $\begin{array}{l}\text { Strengh - Ex- } \\
\text { tension (kg) }\end{array}$ & $12.9 \pm 3.0$ & $16 \pm 2.6$ & $20.4 \pm 2.2$ & $32.67 \pm 3.3^{*}$ & $16.7 \pm 2.3$ & $31.9 \pm 3.1 *$ & .31 & 0.049 & .16 \\
\hline $\begin{array}{l}\text { Strengh - } \\
\text { Row (kg) }\end{array}$ & $14.4 \pm 3.2$ & $14.8 \pm 4.0$ & $26.3 \pm 2.3$ & $34.2 \pm 3.5^{*}$ & $22.6 \pm 2.4$ & $35.5 \pm 3.7 *$ & .62 & 0.038 & .18 \\
\hline
\end{tabular}

\section{Discussion}

It is known that DS is the result of a genetic alteration which causes a series of local and systemic modifications that are expressed in various degrees. However, to what extent this condition changes the time of growth, rate of skeletal maturation (SM) and the possible effects on physical fitness or aspects of body composition in this population, are issues that require more elucidation.

In the present study, the young people with Down syndrome exhibited average SA $16.61 \pm 2.15$ years and CA $15.46 \pm 2.64$ years, with advanced SA in relation to CA. These results are similar to SANTOS et al. (2013), who, using the same method of analysis, found that 85 people with DS between 5 and 15 presented advanced SA compared to CA. In another study, $\mathrm{RoTCH}^{14}$ found that the skeletal maturation and skeletal growth of people with Down syndrome are accelerated compared to individuals who do not have this kind of genetic alteration.

This condition was also reported by MORAES et al. ${ }^{13}$, who stated that during the early stages of SM, individuals with Down syndrome tend to present delayed SAs below CA, however, during the later stages of SM, these individuals tend to present advanced SA compared to CA. Their research in 40 individuals with DS found that at age 15 the SA of young people with Down syndrome was advanced in relation to CA. This was also observed in the present study, with $55 \%$ of young people featuring advanced SA compared to their CA. In addition, when SA was verified by sex, a higher prevalence of advanced SA was observed in this study for girls (53\%) than boys (45\%). This means that they have a short period of development with early skeletal maturation when compared to individuals without DS, who usually present an end of maturation at around 18 years of age.

The main finding of this study was that skeletal maturation, assessed through skeletal age (SA), influenced body weight, BMI and muscle strength of individuals with DS subjected to 12 weeks of aerobic or resistance training. Although the training 
did not alter body composition, significant increases in time to exhaustion and muscle strength of the lower and upper limbs were observed for both the AT and RT groups. It is speculated that the effect seen in cardiorespiratory fitness was due much more to the reduction in $\mathrm{VO}_{\text {2peak }}$ in the $\mathrm{CG}$ group than the increase in this component of physical fitness in the experimental groups.

For some variables of physical fitness and health, worse body composition results have been observed in young people with Down syndrome compared to their peers without disabilities, with lower levels of lean body mass and increased fat mass $^{31}$. In this sense, exercise programs performed by this population have contradictory effects on body composition ${ }^{31-35}$. CASEY and RASMUSSEN ${ }^{36}$ found in their review a limited influence of physical exercise on body composition of individuals with intellectual disabilities, highlighting the importance of attending to other factors such as nutritional habits.

The studies of Varela, Sardinha and Pitetti ${ }^{35}$ with 16 young people with Down syndrome and an average age of 21.3 years using a rowing ergometer training program for 16 weeks, and of GonZalez-Aguero et al. ${ }^{31}$ after a combined training (strength training) program of 21 weeks with 26 young people with Down syndrome, found no improvement in body fat for this population at the end of the programs. Other studies, however, observed positive results with a reduction in body fat after a training period in young people with DS. SAVUCU ${ }^{34}$ found an average reduction of $7 \%$ in body fat, which was assessed using the bioelectrical impedance method, after 12 weeks of aerobic and resistance training. ORDOŇEZ, ROSETY and ROSETYRoDrIGUEZ ${ }^{33}$, using combined training (water and running), also found body fat reduction after 12 weeks of training. However, it is noteworthy that neither study included a control group in the analysis.

In this context, the present study found no reduction in body fat after 12 weeks of training in young people with DS. However, although the physical training did not cause changes in the morphological structure, it promoted the maintenance of values for the AT and RT groups while the CG group presented an increase in the absolute values of body adiposity and AC. Regarding skeletal maturation, this had a significant influence on the effects of training for body mass variables, $\mathrm{F}(1,38)=4.99 ; \mathrm{p}=.032 ; \mathrm{r}=.34$, and BMI, $\mathrm{F}(1$,
38) $=5.92 ; \mathrm{p}=.02 ; \mathrm{r}=.36$, as shown in TABLE 2 .

The anthropometric indicators $\mathrm{BMI}$ and $\mathrm{AC}$ have been used as parameters for body composition and possible health status of people with and without disabilities. In this regard, a recent study of BANDINI et al. ${ }^{37}$ determined the validity of this parameter to identify excess adiposity in young people with DS, using as a basis the cutoff points of the Center for Disease Control and Prevention ${ }^{38}$, considering the cutoff points above the $95^{\text {th }}$ and $85^{\text {th }}$ percentiles.

This study found a prevalence of $65.8 \%$ of individuals above the $85^{\text {th }}$ percentile when analyzing BMI, which put them at risk in accordance with international criteria. As an aggravating factor, about $40 \%$ of the individuals were above the $95^{\text {th }}$ percentile and therefore more prone to increased risk of diseases such as obesity and other secondary and chronic conditions caused by physical inactivity. Studies such as those of STYLES et al. ${ }^{39}$ and Van Oosterom-Gameren et al. ${ }^{2}$, conducted in the Netherlands, UK and Ireland, reported that more than $55 \%$ of the syndromic population presents overweight and/or obesity, which again reinforces the very high prevalence of data of this condition among young people with Down syndrome.

Regarding muscular strength, this may reflect not only the health status of the individual, but also their level of physical fitness. Studies report that people with Down syndrome showed up to 50\% less capacity to generate strength in the muscles than their peers without disabilities, including people with intellectual disabilities but without $\mathrm{DS}^{40}$. Accordingly, SchneIder, Rodrigues and MEYER ${ }^{9}$, state that maturation can also have an impact on muscle strength in young people without disabilities. The authors found that the strength of pubescent boys was about 30\% higher than that of pubescent girls and reached $77 \%$ higher than the strength of prepubescent boys. However, there are no studies that have related maturation to the development of muscle strength in young people with DS.

Still regarding the performance of muscle strength, CABreza-Ruiz et al. ${ }^{8}$ reported that there is a performance increase in this variable as children grow and that this increase is linked to improvement in neural and biological factors. However it is known that these changes occur in different rhythms and intensities, according to the experiences and stage of life in which the individual is. Thus, ROWLAND ${ }^{10}$ reports that achieved level of performance is more dependent on SA than 
$\mathrm{CA}$, and that maturational status influences the performance level in the population with and without disabilities.

This information corroborates with our results, which indicate a positive influence of SA on the muscular strength indicators of lower and upper limbs in young people with DS. Considering the DS characteristics with respect to muscle hypotonia and early skeletal maturation in this population, children with DS can reach puberty with little increase in skeletal growth. This can be seen clearly by the stature of these individuals in relation to people without disabilities. The importance of checking and paying attention to the maturation levels of children and adolescents with DS is worth highlighting, particularly when it concerns the exercise context since the conditions of the attributes of physical fitness and training response may be influenced by the maturation state.

Regarding the $\mathrm{VO}_{2 \text { peak }}$ values, the peak oxygen consumption was homogeneous pre-training for all groups; however, post-training the CG presented $\mathrm{VO}_{2 \text { peak }}$ values significantly lower than the other two groups. Observing TABLE 2, it is possible to note that the training was not able to improve the values of this variable; on the other hand, the group that did not receive the training demonstrated significantly reduced $\mathrm{VO}_{2 \text { peak }}$ values in only 12 weeks. Despite the training effects on $\mathrm{VO}_{2 \text { peak }}$ not having been observed, a significant increase in the time in which young people submitted to training were able to remain in the effort test was found.

Studies such as those of Varela, Sardinha and Pitetti $^{35}$ and Millar, Fernhall and Burkett ${ }^{41}$, who performed aerobic training for 16 and 10 weeks respectively, did not verify increases in $\mathrm{VO}_{2 \text { peak }}$ in the participants. TSIMARAS, GIAGAZOGLOU and FOTIADOU ${ }^{42}$ suggest that this fact may be due to inadequate exercise intensity. However, in the present study, the intensity of the AT group was monitored using heart rate monitors and the intensity was maintained throughout the set time. The RT training group, despite the increase in subjective load, was constantly controlled so that the loads were adjusted in order that individuals could perform only 12 repetitions maximum.

However, CASAJUs et al. ${ }^{32}$ observed an increase in peak $\mathrm{VO}_{2}$ (pre $32.5 \mathrm{ml} / \mathrm{kg} / \mathrm{min}$ x post $\mathrm{x} 42.0$ $\mathrm{ml} / \mathrm{kg} / \mathrm{min}$ ) after 30 weeks training twice a week with an hour per session. Young people practiced athletics, basketball, volleyball, soccer or handball once a week and swimming in the other session.
SAVUCU ${ }^{34}$ also found improvements in peak $\mathrm{VO}_{2}$ (pre $20.91 \mathrm{ml} / \mathrm{kg} / \mathrm{min} x$ post $22.35 \mathrm{ml} / \mathrm{kg} / \mathrm{min}$ ) after 12 weeks of aerobic training, which consisted of 30-minutes walking on an athletics track without specific intensity. The evaluation method in this study, however, was indirect (Shuttle-run $16 \mathrm{~m}$ ). It is noteworthy that the procedures were different in the studies, and therefore the results need to be considered with caution due to the difficulties in establishing comparisons.

Although many researchers have found little or no changes in $\mathrm{VO}_{2 \text { peak }}$ in young people with DS after exercise, ROWLAND ${ }^{10}$ presented a number of studies in their review and found that those with longer periods presented $\mathrm{VO}_{2 \text { peak }}$ increases. Thus, we believe that the lack of improvement in this variable in the present study could be linked to the relatively short period of the training protocol (12 weeks).

This study had some limitations, such as the convenience selection of the sample, the relatively small number of participants in the groups and the limited intervention time, factors that may have led to difficulties in data analysis and observations of larger effects of training. However, the data collected here brings relevant information about the possible influence of maturation on physical fitness of young people with DS, and strengthens the fundamental role of physical exercise in maintaining positive health in this population.

We can conclude that the effects of physical training on physical fitness of young people with Down syndrome appear to improve as the bone age increases. In addition, the muscle strength of upper and lower limbs increased significantly after 12 weeks of aerobic or resistance training. On the other hand, young people with Down syndrome who do not participate in physical exercise programs can demonstrate significant reductions in cardiorespiratory fitness in a short period of time.

Although maturational status influences the level of physical performance in people both with and without disabilities, it is believed to be very important for health professionals to have information on the aspects of this variable in individuals with DS, since this may provide theoretical and practical support for their professional activities. We suggest that further studies involving individuals with Down syndrome to be conducted in different training situations involving multiple assessments of skeletal maturation in order to better understand how this influences the improvement of the physical fitness variables in this population. 


\section{Resumo}

Influência da maturação esquelética na aptidão física de jovens com síndrome de Down

Indivíduos com síndrome de Down (SD) tendem a atingir prematuramente o período de maturação esquelética. Além disso, jovens com esta condição possuem aptidão física precária e poucas oportunidades de praticar atividade física quando comparados àqueles sem deficiência. 0 objetivo deste estudo foi investigar a maturação esquelética de jovens com síndrome de Down e sua influência no comportamento da aptidão física relacionada à saúde, após programas de treinamento aeróbio e resistido. Quarenta pessoas com SD, com idade média de 15.4 ( \pm 2.6) anos, foram divididas em três grupos para um programa de 12 semanas de intervenção: TA - treinamento aeróbio (3 sessões/semana; 50 minutos/sessão), TR - treinamento resistido (duas sessões/semana ; 50 minutos/sessão) e GC - grupo controle, 9 participantes. A determinação da idade esquelética (IE) foi realizada utilizando o método Greulich-Pyle. Foram mensuradas variáveis antropométricas, força muscular e $\mathrm{VO}_{2}$ pico antes e após a intervenção. Foi visto que a maturação esquelética influenciou os efeitos do treinamento, sendo significante apenas para as variáveis massa corporal e força na remada alta. Além disso, a força muscular dos membros superiores e inferiores cresceu significativamente após 12 semanas de treinamento aeróbio ou resistido. Assim, pode-se concluir que os efeitos do treinamento na aptidão física de jovens com SD parece melhorar à medida que a idade óssea aumenta.

PalavRas-Chave: Exercício Físico; Deficiência Intelectual; Aptidão Física; Idade Esquelética.

\section{References}

1. Mahajan S. Evaluation of skeletal maturation by comparing the hand wrist radiograph and cervical vertebrae as seen in lateral cephalogram. Indian J Dental Res. 2011;22(2):309-16.

2. van Gameren-Oosterom HB, van Dommelen P, Schönbeck Y, Oudesluys-Murphy AM, van Wouwe JP, Buitendijk SE. Prevalence of overweight in Dutch children with Down syndrome. Pediatrics. 2012;130(6):e1520-e1526.

3. Schalock RL, Borthwick-Duffy SA, Buntinx WHE, Coulter DL, Craig EM. Intellectual Disability: Definition, Classification, and Systems of Supports. 11th ed. Maryland: American Association on Intellectual and Developmental Disabilities; 2010.

4. Chen C, Ringenbach D, Snow M. Treadmill walking effects on grip strength in young men with Down syndrome. Res Dev Disabil. 2014;35(2):288-93.

5. Lana-Elola E, Watson-Scales S, Fisher E, Tybulewicz V. Down syndrome: searching for the genetic culprits. Dis Model Mech. 2011;4(5):586-95.

6. Bala M, Pathak A, Jain R. Assessment of skeletal age using MP3and hand-wrist radiographs and its correlation with dental and chronological ages in children. J Indian Soc Pedod Prev Dent. 2010;28(2):95.

7. Rai V, Saha S, Yadav G, Tripathi AM, Grover K. Dental and skeletal maturity- a biological indicator of chronologic age. J Clin Diagn Res. 2014;8(9):60-4.

8. Cabreza-Ruiz R, Garcia-Masso X, Centeno-Prada RA, Beas-Jimenez JD, Colado JC, Gonzales LM. Time and frequency analysis of the static balance in young adults with Down syndrome. Gait \& Posture. 2011;33(1):23-8.

9. Schineider P, Rodrigues LA, Meyer F. Dinamometria computadorizada como metodologia de avaliação da força muscular de meninos e meninas em diferentes estágios de maturidade. Rev Paul Educ Fis. 2002;16(1):35-42.

10. Rowland TW. Fisiologia do exercício na criança. 2a ed. Barueri: Manole; 2008.

11. Armstrong N, Welsman JR. Peak oxygen uptake in relation to growth and maturation in 11- to 17-year-old humans. Eur J Appl Physiol. 2011;85(6):546-51.

12. Calfee RP, Sutter M, Steffen JA, Goldfarb CA. Skeletal and chronological ages in American adolescents: current findings in skeletal maturation. J Child Orthop. 2010;4(5):467-70.

13. Moraes ME, Tanaka JL, Moraes LC, Filho EM, Melo CJC. Skeletal age of individuals with Down syndrome. Spec 
Care Dentist. 2008;28(3):101-6.

14. Rotch T. Chronologic and anatomic age in early life. J Am Med Assoc. 1908;51(15):1197-205.

15. Soegiharto BM, Cunningham SJ, Moles DR. Skeletal maturation in Indonesian and white children assessed with hand-wrist and cervical vertebrae methods. Am J Orthod Dentofacial Orthop. 2008;134(2):217-26.

16. Dodd KJ, Shields NA. Systematic Review of the Outcomes of Cardiovascular exercise programs for people with Down syndrome. Arch Phys Med Rehabil. 2005;86(10):2051-8.

17. Rimmer JH, Marques AC. Physical activity for people with disabilities. The Lancet. 2012;380(9851):1384-5.

18. Wuang YP, Su CY. Patterns of participation and enjoyment in adolescents with Down Syndrome. Res Dev Disabil. 2012;33(3):841-8.

19. Seron BB, Greguol M. Assessment protocols of maximum oxygen consumption in young people with Down syndrome - A review. Res Dev Disabil. 2014;35:676-85.

20. Balic MG, Mateos EC, Blasco CG. Physical Fitness Level of Physical Active and sedentary adults with Down Syndrome. Adapt Phys Activ Q. 2000;17(3):310-21.

21. Associação Brasileira de Empresas de Pesquisa [ABEP]. Critérios de Classificação Econômica Brasil. São Paulo: Associação Brasileira de Empresas de Pesquisa; 2010.

22. Fernhall B, Pitetti KH, Rimmer JH, Mccubbin JA, Rintala P, Millar AL, et al. Cardiorespiratory capacity of individuals with mental retardation including Down syndrome. Med Sci Sports Exerc. 1996;28(3):366-71.

23. Brow LE, Weir JP. ASEP procedures recommendation I: Accurate assessment of muscular strength. Prof Exerc Physiol. 2001;4(3):1-21.

24. Shields N, Taylor NF, Dodd KJ. Effects of a community based progressive resistance training program on muscle performance and physical function in adults with Down syndrome: a randomized controlled trial. Arch Phys Med Rehabil. 2008;9:1215-20.

25. Fess EE, Moran C. Clinical Assessment Recommendations. Philadelphia: American Society of Hand Therapists; 1981.

26. Winnick J, Short F. Brockport Physical Fitness Test (BPFT). Illinois: Human Kinetics; 1999.

27. Greulich WW, Pyle SI. Radiographic atlas of skeletal development of hand and wrist. 2nd ed. Stanford: Stanford University Press; 1959.

28. Malina R, Silva MJC, Figueiredo AJ, Carling C, Beune GP. Interrelationships among invasive and non-invasive indicators of biological maturation in adolescent male soccer players. J Sports Sci. 2012;30(15):1-13.

29. Amerincan College Sports Medicine. Progression models in resistance training for healthy adults. Med Sci Sports Exerc. 2009;41(3):687-708.

30. Fernhall B, Millar AL, Tymeson GT, Burkett LN. Maximal exercise testing of mentally retarded adolescents and adults: reliability study. Arch Phys Med Rehabil. 1990;71(13):1065-8.

31. Gonzalez-Aguero A, Vicente-Rodriguez G, Gomez-Cabello A, Ara I, Moreno LA, Casajús JA. A combined training intervention programme increases lean mass in youths with Down syndrome. Res Dev Disabil. 2011;32(6):2383-8.

32. Casajus J, Pueyo D, Vicente-Rodriguez G, Gonzalez-Aguero A. Mejoras de lacondicióncardiorrespiratoriaenjóvenescon síndrome de Down mediante entrenamiento aeróbico: estudio longitudinal. Apunts Med de l'Esport. 2012;47(174):4954.

33. Ordonez FJ, Rosety M, Rosety-Rodriguez M. Influence of 12-week exercise training on fat mass percentage in adolescents with Down syndrome. Med Sci Monit. 2006;12(10):CR416-CR419.

34. Savucu Y. Influence of 12-Week Training on Aerobic Capacity and Respiratory Functions of Adolescents with down Syndrome. World Appl Sci J. 2010;11(10):1292-6.

35. Varela AM, Sardinha LB, Pitetti KH. Effects of an aerobic rowing training regimen in young adults with Down syndrome. Am J Ment Retard. 2001;106(2):135-44.

36. Casey AF, Rasmussen R. Reduction measures and percent body fat in individuals with intellectual disabilities: a scoping review. Disabil Health J. 2013;6(1):2-7.

37. Bandini LG, Fleming RK, Scampini R, Gleason J, Must A. Is body mass index a useful measure of excess body fatness in adolescents and young adults with Down syndrome? J Intellect Disabil Res. 2013;57(11):1050-7.

38. Center for Disease Control and Prevention (CDC). Growth Charts for the United States: Methods and Development. 
Maryl: National Center for Health Statistics; 2000. (Vital and Health Statistics Series; 11).

39. Styles ME, Cole TJ, Dennis J, Preece MA. New cross sectional stature, weight, and head circumference references for Down's syndrome in the UK and Republic of Ireland. Arch Dis Child. 2002;87(2):104-8.

40. Cowley P, Ploutz-Snyder LL, Baynard T, Heffernan K, Jae YS, Hsu S, et al. Physical fitness predicts functional tasks in individuals with Down Syndrome. Med Sci Sports Exerc. 2010;42(2):388-93.

41. Millar AL, Fernhall B, Burkett LN. Effects of aerobic training in adolescents with Down syndrome. Med Sci Sports Exerc. 1993;25(2):270-4.

42. Tsimaras V, Giagazoglou P, Fotiadou E. Jog-walk training in cardiorespiratory fitness of adults with Down syndrome. Percept Mot Skills. 2003;96(3):1239-51.

\begin{tabular}{r|r} 
CoRRESPONDING AUTHOR: & \\
Márcia Greguol & \\
Rodovia Celso Garcia Cid, Pr 445 Km 380 & Submitted: 23/06/2017 \\
Campus Universitário & Submina \\
Londrina - PR - BRAZIL & Accepted: 20/09/2017 \\
CEP: 86.057-970 & \\
E-mail: mgreguol@gmail.com &
\end{tabular}

